\title{
Molecular Characterization of Klebsiella Pneumonia in Clinical Isolates with High Resistance toward Carbapenemases
}

\section{Piero Aloisi ${ }^{1}$, Mattia Manelli ${ }^{1}$, Ramona Iseppi ${ }^{2}$ and Carla Sabia ${ }^{2+}$}

${ }^{1}$ Hesperia Hospital, Laboratory of Clinical Chemistry and Microbiology Modena, Italy

${ }^{2}$ Department of Life Sciences, University of Modena and Reggio Emilia, Modena, Italy

\begin{abstract}
Carbapenem-resistant Enterobacteriaceae (CRE) is spreading in worldwide and has become endemic in several countries, including Italy $[1,2]$. The global dissemination of carbapenem-resistant Enterobacteriaceae is mostly due to strains of Klebsiella pneumoniae and less frequently of other species producing various types of acquired carbapenemases [3]. However, antimicrobials (such as carbapenems, cephalosporin) which are widely used in the treatment of $K$. pneumoniae infection have been proven to be a major factor to mortality and morbidity in settings with limited diagnostic facilities and treatment options [4], especially in increasing emergent multidrug resistant (MDR) K. pneumoniae. MDR K. pneumoniae, internationally defined as having non-susceptibility to at least three classes of antibiotics or more [5], poses tremendous threat to clinical setups in hospitals. Resistance to carbapenem by such enzyme is a global concern due to limited therapeutic options and their association with life-threatening infections. Large referral hospitals and teaching institutions are at great risk for a widespread outbreak of infections and responsible for the spread of such strains from one location to another and to other hospitals. Experiences in individual hospitals or in whole countries they have shown how it is possible to eradicate or contain strongly the spread of Enterobacteria strains producing carbapenemases through aggressive infection control interventions in the health sector, aimed at promptly identifying cases of clinically evident infections and colonized patients and promptly adopting stringent measures of containment of dissemination (isolation of colonized or infected patients, hand hygiene, cleaning and environmental contamination, etc.) [6].
\end{abstract}

In this report we present the phenotypic and molecular characterizations of KPC-producing carbapenem-resistant $K$. pneumonia clinical isolates in an Italian hospital.

The study included thirty-eight isolates obtained from the following samples: rectal swab $(n=14)$, urine $(n=10)$, bronchoalveolar lavage $(\mathrm{BAL} ; \mathrm{n}=8)$ and wound swab $(\mathrm{n}=6)$.

Species identification and antimicrobial susceptibility testing were carried out using the Vitek 2 system and the ASTGN201 cards (bio Merieux, Florence, Italy).

Carbapenemase production was confirmed by a disc diffusion synergy test including meropenem and two carbapenemaseinhibiting compounds (ethylenediaminetetraacetic acid EDTA, and boronic acid) [7].

PCR screening was performed with cell lysates for identification of the carbapenemase genes using specific bla primers designed for identifying known $\beta$-lactamase genes including, $b l a_{\mathrm{KPC}} ; b l a_{\mathrm{IMP}}$, $b l a_{\mathrm{VIM}}, b l a_{\mathrm{OXA} 48}, b l a_{\mathrm{NDM}}[8,9]$ cellular debris were removed by centrifugation at $17,310 \mathrm{~g}$ for $5 \mathrm{~min}$. aliquot of $2 \mu \mathrm{l}$ of the supernatant used as DNA template for PCR [10]. PCR-positive amplicons were purified by the QIA quick PCR Purification Kit according to the manufacturer's instructions (Qiagen, Milan, Italy) and directly sequenced using amplification primers on the 3130 Genetic Analyzer (Applied Biosystem, Milan, Italy). Purification and sequencing were

\section{Publication History:}

Received: March 20, 2018

Accepted: June 04, 2018

Published: June 06, 2018

\section{Keywords:}

Antibiotic-resistance, Klebsiella pneumoniae, KPC, Molecular genetics

carried out by Genexs.r.o. (CZ, Czech Republic). Sequence alignment and analysis were performed online using the BLAST program of the National Center for Biotechnology Information (www.ncbi.nlm.nih. gov).

The K. pneumonia isolates underwent molecular typing by means of the MLST technique were performed using seven conserved housekeeping genes (gapA, infB, mdh, pgi, phoE, rpoB, tonB) [11]. A detailed protocol of the MLST procedure, including allelic type and sequence type (ST) assignment methods, is available in MLST databases from Pasteur Institute, Paris, France at the following website (http:// www.pasteur.fr/recherche/genopole/PF8/mlst/Kpneumoniae.html).

MICs of imipenem and meropenem in the range of $4 \mathrm{mg} / \mathrm{L}$ to $\geq 16$ $\mathrm{mg} / \mathrm{L}$ and $1 \mathrm{mg} / \mathrm{L}$ to $\geq 16 \mathrm{mg} / \mathrm{L}$, respectively, were observed. The tested strains were analyzed for the presence of resistance mechanisms against $\beta$-lactam antibiotics using PCR amplifications for bla genes responsible for carbapenemases production $\left(b l a_{\mathrm{KPC}}, b l a_{\mathrm{VIM}}, b l a_{\mathrm{IMP}}\right.$, $b l a_{\mathrm{NDM}}$ and $\left.b l a_{\mathrm{OXA}-48}\right)$.

Overall, 38 out of the 34 isolates were positive for the $b l a_{\mathrm{KPC}}$ gene, 2 for the $b l a_{\mathrm{VIM}}$ metallo-b-lactamase and 2 for the $b l a_{\mathrm{OXA}-48}$ gene; while all were negative for NDM gene. Sequence analysis of the entire genes revealed perfect identity with the $b l a_{\mathrm{KPC}-2}(20 / 38), b l a_{\mathrm{KPC}-3}(18 / 38)$, $b l a_{\mathrm{VIM}-1}(2 / 18)$ and $b l a_{\mathrm{OXA}-48}(2 / 38)$ genes.

Multi Locus Sequence Typing showed that the ST258 clone was typical of the KPC-2 producing strains, while the ST512 clone was characteristic of the 5 bla $_{\mathrm{KPC}-3}$ producing strains, were previously reported in Italy $[12,13]$.

Recognition of different carbapenem-non-susceptible clones by molecular epidemiological tools is an important step towards tracing transmission routes, developing targeted control and prevention strategies, and monitoring their effectiveness.

*Corresponding Author: Dr. Carla Sabia, Department of Life Sciences, University of Modena and Reggio, Via Campi 28741125 Modena, Italy, Tel: (+39) 059 2055748; Fax: (+39) 059 2055483,E-mail: carla.sabia@unimore.it

Citation: Sabia C, Aloisi P, Manelli M, Iseppi R (2018) Molecular Characterization of Klebsiella Pneumonia in Clinical Isolates with High Resistance toward Carbapenemases. Int J Clin Med Microbiol 3: 131. doi: https://doi. org/10.15344/2456-4028/2018/131

Copyright: (C) 2018 Sabia, et al. This is an open-access article distributed under the terms of the Creative Commons Attribution License, which permits unrestricted use, distribution, and reproduction in any medium, provided the original author and source are credited. 
Citation: Sabia C, Aloisi P, Manelli M, Iseppi R (2018) Molecular Characterization of Klebsiella Pneumonia in Clinical Isolates with High Resistance toward Carbapenemases. Int J Clin Med Microbiol 3: 131. doi: https://doi.org/10.15344/2456-4028/2018/131

In addition, the KPC and IMP genes are usually associated with mobile genetic elements that can efficiently disseminate to other bacteria in the hospital environment [14,15]. It is therefore important to emphasize the prompt recognition and establishment of proper therapeutic and infection control measures in order to reduce the spread of infections caused by these highly resistant organism.

The accurate detection of this emerging public health threat clone is crucial both for the selection of appropriate therapeutic regimens and for controlling the spread of KPC-type enzymes.

\section{Competing Interests}

The authors declare that they have no competing interests.

\section{References}

1. Rossolini GM (2015) Extensively drug-resistant carbapenemase-producing Enterobacteriaceae producing carbapenemases: an emerging challenge for clinicians and healthcare systems. J Intern Med 277: 528-531.

2. Nordmann P, Poirel L (2014) The difficult-to-control spread of carbapenemae producers in Enterobacteriaceae worldwide. ClinMicrobiol Infect 20: 821-830.

3. Tängdén T, Giske CG (2015) Global dissemination of extensively drugresistant carbapenemase-producing Enterobacteriaceae: clinical perspectives on detection, treatment and infections control. J Intern Med 277: 501-512.

4. Christine FN, David PK, Henry M, Moses LJ, Sabiha YE, et al. (2016) Antimicrobial susceptibility profiles of Escherichia coli and Klebsiella pneumoniaeisolated from outpatients in urban and rural districts of Uganda. BMC Res. Notes 9: 235

5. Magiorakos AP, Srinivasan A, Carey RB, Carmeli Y, FalagasME, et al. (2012) Multidrug-resistant, extensively drug-resistant and pandrug-resistant bacteria: an international expert proposal for interim standard definitions for acquired resistance. ClinMicrobiol Infect 18: 268-281.

6. Bartolinia A, Bassoa M, Franchina E, Menegottoa N, Ferraria A, et al. (2017) Prevalence, molecular epidemiology and intra-hospital acquisition of Klebsiella pneumoniae strains producing carbapenemases in an Italian teaching hospital from January 2015 to September 2016. Int J Infect Dis 59: 103-109.

7. Sakris A, Kristo I, Poulou A, Themeli-Digalaki K, Ikonomidis A, et al. (2009) Evaluation of boronic acid disk tests for differentiating KPC-possessing Klebsiella pneumoniae in the clinical laboratory. J Clin Microbiol 47:362367.

8. Dallenne C, Da Costa A, Decré D, Favier C, Arlet G, et al. (2010) Development of a set of multiplex PCR assays for the detection of genes encoding important b-lactamases in Enterobacteriaceae. J Antimicrob Chemother 65 : 490-495.

9. Nordmann P, Poirel L, Carrër A, Toleman MA, Walsh TR, et al. (2011) How to Detect NDM-1 Producers. J ClinMicrobiol 49:718-721.

10. Perez-Perez JF, HansonND (2002) Detection of plasmid-mediated AmpC beta-lactamase genes in clinical isolates by using mulpiplex PCR. ClinMicrobiol 40: 2153-2162.

11. Diancourt L, PassetV, Verhoef J, Grimont PA, BrisseS, et al. (2005) Multilocus sequence typing of Klebsiella pneumoniae nosocomial isolates. J ClinMicrobiol 43: 4178-4182.

12. Migliavacca $R$, Nucleo $E$, Asticcioli $S$, Casari $E$, Bracco $S$, et al. (2012) Multifocal diffusion of a KPC-3 producing ST512 K. pneumoniae clone in Northern Italy. New Microbiol 36: 109-110.

13. Giani T, Pini B, Arena F, Conte V, Bracco S, et al. (2013) Epidemic diffusion of KPC carbapenemase-producing Klebsiella pneumoniae in Italy: results of the first countrywide survey, 15 May to 30 June 2011. Euro Surveill 18 : 20489-20498.

14. Conlan S, Thomas PJ, Deming C, Park M, Lau AF, et al. (2014) Singlemolecule sequencing to track plasmid diversity of hospital-associated carbapenemase-producing Enterobacteriaceae. Sci Transl Med 6: 254-272.

15. Sheppard AE, Stoesser N, Wilson DJ, Sebra R, Kasarskis A, et al. (2016) Nested Russian Doll-Like Genetic Mobility Drives Rapid Dissemination of the Carbapenem Resistance Gene blaKPC. Antimicrob Agents Chemother 60: 3767-3778. 